\title{
CULTURAS INFANTIS EM TERREIROS DE CANDOMBLE: UM UNIVERSO ARLEQUINAL NA PAULICEIA DESVAIRADA*
}

\author{
Babalorixá Antônio Paulino de Andrade \\ Ellen Gonzaga Lima Souza
}

\begin{abstract}
Está fundado o Desvairismo [...]
Aliás muito difícil nesta prosa saber onde termina a blangue, onde principia a seriedade. Nem eu sei.
\end{abstract}

(ANDRADE, 2017)

O presente texto nasce do convite de encontros do grupo de estudos em pesquisas em diferenciação sociocultural e do Programa de Pós-graduação em Educação da UNICAMP, com uma interessante perspectiva de abordagem decolonial que intitulava uma aula inaugural de "pós em prosa e ar: culturas infantis em terreiros de candomblé”. Esse convite criou condições para dialogarmos juntos em diferentes formações e possibilidades acerca das produções de culturas infantis nos terreiros de candomblé. Em tempos de ataques abertos à cultura e educação, um convite dessa natureza mostra-se como um oásis de resistência da liberdade de prosear, ter prosa em ar e, sobretudo, de pensar. Portanto, já sabem o que não esperar deste texto, pois não tem como estruturá-lo com a forma "clássica" (introdução, desenvolvimento e considerações); ele está mais para uma costura desordeira, como as nossas manifestações negras de resistência. Costura desordeira, porque vem traçando rumos contrários a uma perspectiva de pensar cartesiano, colonial e neoliberal.

Assim, temos por objetivo dialogar acerca das produções de culturas infantis em um universo arlequinal. De diferentes formas tentamos pensar com as crianças, pois elas nos inspiraram e nos inspi-

*DOI - 10.29388/978-65-86678-02-4-0-f.47-60 
$\operatorname{ram}^{1}$. Nessa prática de pensar com elas, em um mundo adultocêntrico, exige certo desvairismo, afinal, a sanidade está na loucura. Assim, jun tos, vamos recortar fragmentos de reflexões que reconhecem as infâncias como estados e anunciando a sua natureza plural em losangos arlequinais, na perspectiva organizada da desordem paulistana. Esses recortes de fragmentos com reflexões de infâncias serão costurados com os conceitos de lógica exúlica e pedagogia macunaímica ${ }^{2}$.

As crianças nos ensinam a pensar porque nos desestruturam, quebram paradigmas, rompem com a imbecilidade, pois não têm medo da simplicidade. Só uma perspectiva "Macunaímica" poderia reconhecer as crianças em sua inteireza. Por isso, é com simplicidade

\footnotetext{
${ }^{1}$ No referido evento "Pós em prosa e ar: culturas infantis em terreiros de candomblé", exibimos vídeos de algumas crianças dos terreiros cantando para os orixás em diferentes espaços (casa, instituições de educação infantil, etc). A esse respeito, ver o texto: SOUZA, Ellen Gonzaga Lima; COSTA, Daniel Gonzaga. Culturas infantis e Oxóssi: descolonizando com a assertividade do filho de um caçador. Crítica Educativa, v. 5, n. 1, 2019. Disponível em: http://www.criticaeducativa.ufscar.br/index.php/criticaeducativa/issue/view/13. Acesso em: 10 jan. 2020.
}

ARAUJO, Patrício Carneiro; SOUZA, Ellen Gonzaga Lima. Culturas Infantis e Exu: descolonizando as animações com Ayô. In: Catálogo Omo Erê. São Paulo: Prefeitura de São Paulo, 2018.

${ }^{2}$ Lógica Exúlica, descrita em Souza (2016). Só é possível entender a referida lógica exúlica se considerarmos que o indivisível não é uno, mas é múltiplo. O continente africano compreende diversas tradições e não podemos tratá-las como uma única tradição. Hampatê Bâ (2003, p. 1) ressalta, entretanto, que há grandes constantes como "[...] a presença do sagrado em todas as coisas, a relação entre o mundo dos vivos e o mundo dos mortos, o sentido comunitário, o respeito religioso pela mãe”. Por isso, é na indivisão múltipla que se encontra a cosmologia de mundo africana, e esta nos apresenta a lógica exúlica, pois não se separa o sagrado do cotidiano, na medida em que mantêm-se vivos e mortos unidos na comunidade. Essa lógica não permite um raciocínio binário calcado em divisões superficiais, mas, acima de tudo, não se pauta pela obviedade, pois estrutura-se nas singularidades e peculiaridades próprias da ancestralidade inerente a cada pessoa, e é a ancestralidade quem faz o ser humano alguém uno e múltiplo na lógica exúlica.

Pedagogia Macunaímica, contribuição de Faria (1999), inspirada em Mário de Andrade.

"Potência como indeterminação e possibilidade do vir a ser é a essência do que chamamos de princípio exusíaco. Há uma inegável amarração entre Exu e Macunaíma. $\mathrm{Na}$ cultura popular de matriz africana, Exu é princípio do dinamismo e da transformação. Exu é o que quiser, o múltiplo no uno e, por isso, é possuidor de muitos nomes. É também transgressor, desobediente e malandro. Nada se faz sem Exu, nenhuma transformação ou comunicação é possível se não for feita por seu intermédio." (SANGENIS, 2018). 
que buscamos reconhecer, na Pauliceia Desvairada, a existência dos orixás. Qual maior exemplo de loucura para a perspectiva colonial do que o reconhecimento de forças míticas ancestrais africanas em uma metrópole como São Paulo? Mas é justamente pelo seu excesso de gente em seu ar cosmopolita, que fica fácil perceber as influências dos orixás na cidade que não dorme e é tão grande que só podemos pensar em uma regência compartilhada entre todos os Orixás.

É em São Paulo-capital onde Exu se apresenta na ordem da desordem daquela que "és o avesso, do avesso, do avesso, do avesso", forjada por Ogum, presente em sua força e em seu pioneirismo, "sangue, amor e poder" ${ }^{4}$, na qual a fartura de Oxóssi impera (embora desigualmente distribuída), e nas profundezas das estações de metrô nos encontramos com Obaluaê, na temperatura quente dos corpos que se espremem em busca de um lugar; Ossaim aparece nos verdes que insistem e resistem, mostrando que, na busca pela vida, só há uma constante, a mudança! Com Xangô, enfaticamente se anunciando como um trovão presente no tom de realeza das manifestações culturais negras que resistem, no "mais possível novo quilombo de Zumbi"5. Segue cortada pela luminosidade de Oxum, que se reflete nos rios Tietê e Pinheiros, nas marginais onde vemos as imagens das luzes e dos prédios, seja dia, seja noite. Com as ventanias que reapresentam Iansã, ao mudar o clima repentinamente, na temperatura ou nos temperamentos; na entrega desmedida de Iemanjá, presente em cada morador da cidade "e na medida do impossível, tá dando para se viver na cidade de São Paulo, o amor é imprevisível como você e eu e o céu" ${ }^{6}$. Por fim, anunciando em cortejo, talvez o orixá que se faz mais visível nesta cidade, Oxalá, dono do progresso, aquele que quando tudo está em "ordem" derruba e nos convoca a fazer melhor do que antes, intensamente vivo na inquietude de cada habitante da Pauliceia Desvairada. Talvez discordem, por não reconhecerem que este está embaixo de um grande

\footnotetext{
${ }^{3}$ Alusão à música Sampa, interpretação de Caetano Veloso.

${ }^{4}$ Alusão à música $\hat{E}$... São Paulo - SP, interpretação de Fernanda Abreu.

${ }^{5}$ Segunda alusão à música Sampa, interpretação de Caetano Veloso.

${ }^{6}$ Alusão à música Lá vou eu, interpretação de Rita Lee.
} 
alá ${ }^{7}$ que, em São Paulo, não está tão branco como se espera de um alá de Oxalá, mas está cheio de esperanças e expectativas, afinal já anunciada e cantada como "terra da garoa".

Conforme destacado por Souza; Tebet; Andrade (2019, p. 37), a opção pela compreensão de significados de infâncias no candomblé, especialmente em uma cidade como São Paulo-capital, com um histórico marcado por sua forma cosmopolita, tem por objetivo colaborar com a construção de justiça cognitiva e reconhecimento de outras epistemologias que não são compreendidas em uma perspectiva abissal, binária, cartesiana e eurocêntrica, marcando a resistência da cosmogonia de nagô na metrópole brasileira.

E é a partir de São Paulo, que tem como lema na bandeira da cidade Non Ducor Duco, "não sou conduzido, conduzo", que tentaremos nos conduzir com as crianças, pois estas nos ensinaram que a melhor forma de aprender-ensinar-aprender candomblé é brincando, cantando, tocando e dançando. O referido lema da bandeira paulistana poderia ser a exemplificação de como as crianças se organizam e nos reorganizam, conforme fizeram com a metodologia de Souza (2016, p.93): "Então Paula falou: 'Já sei tia você esqueceu como é ser criança, porque ficou velha!' Falei: 'É isso mesmo!'. Então Pedro disse: 'Não tem problema, a gente te ensina é só você brincar' ".

Não fujo do ridículo, tenho companheiros ilustres. (ANDRADE, 2017, p.11)

Em um universo adultocêntrico, ao olharmos com as crianças, nossas percepções exigem palavras que reforcem os conceitos de insanidade. Talvez porque as amarras cartesianas binárias que opõem homens a mulheres e adultos às crianças nos façam opor sanidade à loucura, e obviamente o lugar da irracionalidade acaba por ser atribuído às crianças, justamente aquelas figuras que resistem e se rebelam dian-

\footnotetext{
${ }^{7}$ Pano branco que cobre Oxalá nas festas de candomblé.

${ }^{8}$ Alusão à música $\hat{E}$... São Paulo, interpretação Alvarenga e Ranchinho.
} 
te da repressão com muito mais avidez do que qualquer adulto adestrado.

Nessa direção, a pesquisa de Faria (1999) anuncia, por meio de Mário de Andrade, que a linguagem poética, não acadêmica, permite alcançar para a área da Educação uma perspectiva mais equânime. Assim, é isso que no prosear buscamos, talvez com as crianças possamos sair da insana necessidade de classificação e binarismo postos pela perspectiva cartesiana rumo à justiça cognitiva.

Mário é macunaímico. E, assim como ele, o Brasil: uma identidade que não é uma; sua especificidade está na indefinição que, por sua vez, reúne muitas definições e muitas especificidades; possibilita aos opostos se encontrarem; “sem nenhum caráter" é a pluralidade de caracteres diversos. Pensando dessa forma, é que foi possível pensar a criança de uma maneira diferente das usuais: o fato de a criança não falar, ou não escrever, ou não saber fazer as coisas que os adultos fazem transforma-a em produtora de uma cultura infantil, justamente através "dessa(s)" especificidade(s). A ausência, a incoerência e a precariedade características da infância, em vez de serem "falta", incompletude, são exatamente a infância (FARIA, 1999, p.77).

A linguagem não acadêmica e a necessidade da arte na discus são acerca das infâncias não é a opção dos/das autores/as para parecer excêntricos/as ou libertários/as, mas é reflexo da impossibilidade de lidar com algum nível de previsibilidade, quando se trata de trabalhar com as crianças e não a respeito delas. Exige outra epistemologia corporal, devemos nos abaixar para olhar juntos e não impor nossa adultez.

Macunaimicamente está posta a exigência da preguiça, “ai que preguiça ${ }^{9 "}$, de fazer coisas sem sentir, para isso a preguiça torna-se um ato de resistência. Assim são as crianças, inquietas em busca de sentidos que só podemos encontrar por meio da arte, que nos permite potencializar todos os nossos sentidos (tato, olfato, audição, paladar e vi-

\footnotetext{
${ }^{9}$ Primeira frase proferida por Macunaíma, personagem de Mário de Andrade (2017).
} 
são). Por isso, a reflexão acerca da cidade de São Paulo implica cantar, dançar e fantasiar essa cidade, assim como as crianças fazem. É interessante que as cenas mais comuns das crianças no candomblé e falando acerca do candomblé fora dos terreiros, em especial nas instituições de ensino, é sempre em torno da música, seja batucando ou dançando elas vão anunciando sua paulistanidade nagô, e como uma enchente inundam as instituições, ocupando-as com a lógica exúlica, que não pede licença, simplesmente entra.

Em nosso recorte arlequinal, há necessidade de mais uma denúncia, pois no dia 6 de fevereiro de 2020, a Secretaria de Educação do Estado de Rondônia ${ }^{10}$ elaborou um memorando com uma relação de livros a serem recolhidos, e dentre eles está a obra Macunaíma, de Mário de Andrade. Essa indicação política não é inócua e nem tampouco reflete desconhecimento da obra, mas, ao contrário, por reconhecer o potencial transgressor de um sistema de opressão colonial que ainda vivemos. Proibir Macunaíma é proibir a brasilidade, é proibir a natureza humana de produzir cultura e fazer arte. Mas, ninguém proibirá as crianças de nos ensinarem a resistir, pois elas continuarão, de forma arteira, a levar nossa brasilidade em seus corpos nas instituições em que estiverem; apesar de todo esforço colonial, não há como aprisionar Exu e sua lógica, afinal, estes antecedem a colonização. Podem proibir Macunaíma, mas não proibiram a nossa multiplicidade.

No texto "As culturas infantis interrogam a formação docente: tessituras para a construção de pedagogias descolonizadoras", Souza; Santiago; Faria (2018) destacam a relevância de compreender como as crianças produzem cultura em um espaço de resistência para dialogar com a construção de outras metodologias. Assim, a cosmogonia nagô apresentada em Souza (2016) reforça que o conceito de criança não se constrói pela oposição semântica com o conceito de adulto, mas se revela como construção da possibilidade de trânsito (portanto, categoria

\footnotetext{
${ }^{10}$ No dia 7 de fevereiro de 2020, após a pressão e as repercussões, a referida secretaria recuou em sua decisão. In: <https://g1.globo.com/ro/rondonia/noticia/ 2020/02/06/documento-da-secretaria-de-educacao-de-ro-manda-recolher-de-escolas-macunaima-e-mais-42-livros-secretario-diz-ser-rascunho.ghtml >. Acesso em: 15 jan. 2020.
} 
não estática), em que movimento, transitividade e narratividade, segundo a Semiótica (LOTMAN, 1996; BAKHTIN, 1999), se inserem na ordem e na natureza do axé, força vital e de permanente movimentação. A infância, nesta propositura, sob a prescrição da lógica de Exu, reporta não a si mesma, mas evoca, polifonicamente, diferentes enunciados de estado (gestação, nascimento, infância, adolescência, juventude, adultez, velhice e ancestralização), estados a que se pode ir e vir, numa perspectiva capaz de sabotar a cognição, a interpretação e a representação simbólica eurocêntrica da percepção do tempo.

Permitirmo-nos sabotar a cognição é condição indispensável para reconhecer as culturas infantis, bem como compreender a poesia posta em uma Pauliceia que jamais seria resistente e condutora se fosse lúcida; ela só é potente porque se admite desvairar, desviar, transitar.

\begin{abstract}
"Este Alcorão nada mais é que uma embrulhada de sonhos confusos e incoerentes. Não é inspiração provinda de Deus, mas criada pelo autor. Maomé não é profeta, é um homem que faz versos. Que se apresente como sinal revelador de seu destino, como os antigos profetas". Talvez digam de mim o que disseram do criador de Alá. Diferença cabal entre nós dois: Maomé apresentava-se como profeta; julguei mais conveniente apresentarme como louco. (ANDRADE, 2017, p.8-9)
\end{abstract}

Na conveniência do reconhecimento da loucura, um capítulo da tese de Souza (2016, p. 136-137), intitulado "Entre a loucura adulta e a sanidade dos erês", é possível compreender que mesmo as pesquisas acerca do candomblé expressam equivocadamente relações cartesianas.

Há uma divergência quanto ao significado da palavra erê; por exemplo, para o babalorixá Toninho de Oxum, está ligada ao brincar, advém de xirê e se relaciona com brincadeira, indica criança, meninos, etc. Segundo Verger (1999, p.84), "No Brasil certos pais-de-santo afirmam que erê é uma contração da palavra asiwere, que em yorubá significa "louco". Esse mesmo estado é classificado pelos nagô da África 
como tinuerde (que chegou nas bagagens), evidenciando muito bem a posição de adjunto, daquele que vem depois.

Assim, não há um consenso quanto ao estado de erê e isso se reflete na dificuldade adultocêntrica de lidar com o universo das infâncias, pois relacionar-se com as crianças, auxiliar os/as adultos/as em transe do orixá, acolher os visitantes, tudo é visto com naturalidade, porém o estado de erê é visto como o mais delicado pelas (os) filhas(os) de santo. Nesse estado, a pessoa faz aquilo que tem vontade e não necessariamente aquilo que lhe é solicitado.

No estado de erê, temos um corpo adulto em um transe infantil; diferentemente das relações que corpos adultos estabelecem com as crianças, relação essa hierárquica, em que adultos colocam objetos fora do alcance de crianças, não olham nos olhos com posturas horizontais e sim verticalizadamente e, por vezes, o tamanho do adulto frente a crianças pode intimidar. O estado de Erê em um corpo adulto confronta outros corpos adultos, porém em uma personalidade infantil.

Acerca do significado de loucura, no contexto do Candomblé, tem-se uma ideia oriunda do estado de loucura patológica, o qual se assemelha ao estado de alter-consciência ou hetero-consciência, que acomete o indivíduo em transe. Todavia, há que se compreender que, no seio do egbé, a comunidade de santo, o termo se ressemantizou, ora perdendo traços de significação (subtração da ideia de "patologia", "insanidade", transtorno, etc., todos de caráter disfórico), ora acrescendo traços de significação (adição da ideia de "espiritualidade", "pueril", "lúdico", etc., todos de caráter eufórico). Assim, o estado de erê representa a "loucura", entendida como a necessária perturbação da ordem estabelecida, adultocêntrica, a objeção necessária à naturalização dos papéis sociais e a prescrição do seu status, a subversão de modelos rígidos para a restauração de um estado e uma disposição social incentivadora de uma circunstância de convívio entre os seres do Orum e do Ayê, entre adultas(os) e crianças, entre os estados de consciência e inconsciência, palco da manutenção dos saberes ancestres, constituído como um fórum em que, num aparente caos, são repensados e reafirmados os laços e os contratos com o sagrado e o secular. 
O estado de erê representa o próximo elo que, permanentemente, precisa se renovar em favor da perpetuação da tradição, em favor de um presente disposto a ser a base do porvir, e em favor de um futuro que necessita, de fato, vir a ser, sob a pena de uma inexorável extinção. Em poucas palavras, erê, o meristema do tecido ideológico do Candomblé, é o último ponto do pé de okotô, condição do crescimento incessante e espiral da concha de caracol de Exu, cuja expansão se inicia em Olorun e não termina jamais, pois a graça de Oxum, a mãe do ovo, o novo sempre vem e virá, nomeando o amanhã: Pilãozinho, Florzinha, Mel, Raio de Sol ${ }^{11}$... Este último, talvez, o primeiro de cada manhã.

Admitimos que o conceito de África é geográfico e não metafísico. Mas, consideramos, como Nietzsche (em Além do bem e do mal), que a geografia é algo a ser levado em conta na perspectiva de outros modos de pensar. E o que apresentamos é a perspectiva de um modo afro de pensar tipificado no sistema nagô, que é de fato uma forma intensiva de existência (forma em que a passagem do biológico ao simbólico ou ao "espiritual" é quantitativamente significativa) com processos filosóficos próprios. "Afro" não designa certamente nenhuma fronteira geográfica e sim a especificidade de processos que assinalam tanto diferenças para com os modos europeus quanto possíveis analogias. (SODRÉ, 2018, p. 16)

Ao reconhecer a lógica exúlica e assumir de forma consciente a loucura, tencionamos alguns estereótipos que cercam a leitura dos intolerantes racistas acerca do candomblé ${ }^{2}$, ou melhor, com a perspectiva nagô de mundo, observam-nos como animistas, consideram-nos como pouco racionais, bem próximos ao que classificam como selvagem (opondo emoção à razão), enojam-se das práticas ritualísticas que nem conhecem e, por isso, temem, tratam com uma noção de pri-

\footnotetext{
${ }^{11}$ Nomes de alguns erês no Ilê Axé Omo Oxé Ibalatam.

${ }^{12}$ Cabe destacar que a palavra candomblé indica reunião, mas cada casa, terreiro ou roça tem suas especificidades e se organiza a partir da liderança.
} 
mitivos e infantis. Mas a centralidade do rito está em ORI, que significa cabeça, orixá quer dizer força para a cabeça, essencialmente culto destinado à razão almeja-se que seus adeptos possam fazer boas escolhas diante das dificuldades da vida. Assim, um culto à razão só é possível assumindo devaneios.

Em permanente consciência dos devaneios inspirados por Exu, "que matou um pássaro ontem com a pedra que hoje atirou", damonos ao luxo de caminhar para a finalização deste prosear com uma cantiga dedicada a Exu, que tradicionalmente é o primeiro a ser saudado.

A jí ki Barabo e mo juba, àwa kò sé

A jí ki Barabo e mo juba, e omodé ko èkó ki

Barabo e mo juba Elegbara a Ėsù l'ònòn

Nós acordamos e cumprimentamos Barabo,

A vós eu apresento meus respeitos,

Que vós não nos façais mal.

A vós eu apresento meus respeitos.

A criança aprende na escola (é educada, ensinada)

(OLIVEIRA, 2009, p.23)

É importante destacar que o texto Cantando para os orixás, de Oliveira (2009), é um dos mais importantes trabalhos de preservação das histórias do povo nagô, e pelo qual temos profundo respeito. Mas aqui cabe iniciar uma discussão a respeito da tradução de uma das poucas cantigas que trazem especificamente a palavra omode, que em yorubá significa criança.

Em nossa compreensão, a tradução ${ }^{13}$ mais adequada para a frase da cantiga de Exu que remete à criança seria "e omode ko èkó ki”, "a criança encontra acaçá denso" e não "a criança aprende na escola”, conforme indicado por Oliveira (2009). Interessante destacar que em todas as outras páginas do texto em que aparece a palavra èkó ${ }^{14} \mathrm{o}$ autor a traduziu como acaçá, contudo, na música em que se menciona a cri-

${ }^{13}$ Com apoio em: BENISTE, José. Dicionário yorubá-português. Rio de Janeiro: Bretrand Brasil, 2011. 
ança, logo remeteu-se à palavra escola, isso é fruto da perspectiva cartesiana de infância que não nos isenta e faz com que institucionalizemos as crianças.

O acaçá é como um alimento ofertado a todos os orixás, feito com milho branco e água, ganha uma consistência próxima a de um pudim; esse alimento é embrulhado em uma folha de bananeira e ganha uma forma de pirâmide. Sem dúvida é o alimento mais utilizado na culinária do candomblé, com diversas finalidades; sua representação é o fortalecimento.

A criança encontra um acaçá denso, assim, acaçá é o fortalecimento para o ciclo da vida, sua cor clara indica uma luminosidade para as nossas reflexões na saudação ao ori e aos orixás. Por isso, o acaçá é o primeiro alimento, seu formato de pirâmide representa um apontamento em direção ao orun, ao alto, para auxiliar as pessoas a encontrarem o caminho, logo, a criança é aquela que encontra maior densidade para conduzir a comunidade.

Sigamos, então, em desvario a condução das crianças, e que estas não nos abandonem em um mundo que se quer são, quadrado, cartesiano, adultocêntrico, racista, patriarcal, homofóbico, pois densidade nas reflexões só é possível com elas.

\section{Referências}

ALVARENGA; RANCHINHO. Ê ... São Paulo. Álbum Caterete. Intérprete Alvarenga e Ranchinho, 1943.

ANDRADE, Mário. Macunaíma. Barueri: Novo Século, 2017.

Pauliceia Desvairada. Barueri: Novo Século, 2017.

ARAUJO, Patrício Carneiro; SOUZA, Ellen Gonzaga Lima. Culturas Infantis e Exu: descolonizando as animações com Ayô. In: Catálogo Omo Erê. São Paulo: Prefeitura de São Paulo, 2018.

\footnotetext{
${ }^{14}$ Exemplo página 134 "A èkó e egé e ìyalóòde iyá awo rò" "Nós lhe oferecemos ecó (acaçá), pois ela pode tornar-se uma perigosa armadilha”, cantiga referente ao orixá Oxum.
} 
BÂ, Amadou Hampâté. Amkollel, o menino fula. Tradução Xina Smith de Vasconcellos. São Paulo. Cassa das Áfricas e Pallas Athena, 2003.

BAKHTIN, Mikhail. Marxismo e Filosofia da Linguagem. 9. ed. São Paulo: HUCITEC, 1999.

BENISTE, José. Dicionário yorubá-português. Rio de Janeiro: Bertrand Brasil, 2011.

CARLINI, Luiz Sérgio; LEE, Rita. Lá vou eu. Álbum Rita Lee \& Tutti Frutti. Intérprete Rita Lee, 1976.

FARIA, Ana Lúcia Goulart de. A contribuição dos parques infantis de Mário de Andrade para a construção de uma pedagogia da Educação Infantil. Campinas. Educação \& Sociedade, ano XX, n. 69, 1999.

FAWCETT, Fausto; ABREU Fernanda, LIMINHA. São Paulo - SP. Álbum Entidade Urbana. Intérprete Fernanda Abreu, 2001.

LOTMAN, Iuri. La se miosfera I: semiótica de la cultura y del texto. Tradução de Desiderio Navarro. Valência: Frónesis Cátedra, 1996.

OLIVEIRA, Altair Bento. Cantando para os orixás. 4. ed, Rio de Janeiro: Pallas, 2009.

SANGENIS, Luiz Fernando Conde. Pedagogia da preguiça: inspirações macunaímica para pensar a escola do Brasil contemporâneo. In: SANGENIS, L.F.C; OLIVEIRA, E.F.R.; CARREIRO, H.J.S., eds. Formação de professores para uma educação plural e democrática: narrativas, saberes, práticas e políticas educativas na América Latina [online]. Rio de Janeiro: EdUERJ, 2018.

SODRÉ, Muniz. Pensar Nagô. Petrópolis: Vozes, 2018.

SOUZA, Ellen Gonzaga Lima. Experiências de infâncias com produções de culturas no Ilê Axé Omo Oxé Ibá Latam. 2016. Tese (Doutorado em Educação) - Universidade Federal de São Carlos, São Carlos, 2016. 
. Bebês, cultura e raça em terreiros de candomblé: diálogos com Hampate Bâ. In: TEBET, Gabriela. Estudos de bebês e diálogos com a sociologia. São Carlos: Pedro \& João Editores, 2019.

SOUZA, Ellen Gonzaga Lima; SANTIAGO, Flávio; FARIA, Ana Lúcia Goulart de. As culturas infantis interrogam a formação docente: tessituras para a construção de pedagogias descolonizadoras. Revista Linhas. Florianópolis, v. 19, n. 39, p. 80-102, jan./abr. 2018.

SOUZA, Ellen Gonzaga Lima; COSTA, Daniel Gonzaga. Culturas infantis e Oxóssi: descolonizando com a assertividade do filho de um caçador. Crítica Educativa, v. 5, n. 1, 2019.

SOUZA, Ellen Gonzaga Lima; TEBET, Gabriela; ANDRADE, Antônio Paulino. Epistemologias do Sul: infâncias e candomblé na cidade de São Paulo em busca de uma pedagogia arteira. In: MACHADO, Maria Izabel. A sociologia e as questões interpostas ao desenvolvimento humano. Organizadora Maria Izabel Machado. Ponta Grossa, PR: Atena Editora, 2019. v.2.

VELOSO, Caetano. Sampa. Álbum Muito dentro da estrela azulada. Intérprete Caetano Veloso, 1978.

VERGER, Pierre. Notas sobre o culto aos orixás e voduns na Bahia de todos os santos, no Brasil, e na antiga costa dos escravos, na África. Tradução: Carlos Eugênio Marcondes de Moura. São Paulo: Universidade de São Paulo, 1999. 
